\title{
Influence of Corrosion on Parameters of Fracture Mechanics of Aluminium Alloys 2024-T351 and 7075-T651
}

\author{
Zoran PETROVIĆ*, Aleksandar GRBOVIĆ, Zijah BURZIĆ, Srđa PERKOVIĆ
}

\begin{abstract}
This paper presents the results of determining the fatigue crack growth parameters in aluminium alloy specimens 2024-T351 and 7075-T651, with different levels of previous corrosion, in the laboratory environment. Tests were performed, under the same load conditions, for each case of corrosion (without corrosion, 7 days of exposure in a corrosive environment and 30 days of exposure in a corrosive environment). All the tests were performed at room temperature. The analysis of the results includes changes in the basic parameters of fatigue crack growth, depending on the time of exposure to the action of controlled moisture. In addition, this paper gives a brief overview of modern design processes in the environment of computer mechanics and presents the results of the crack growth simulation, using the software package ANSYS.
\end{abstract}

Keywords: aluminium alloy 2024-T351; aluminium alloy 7075-T651; corrosion; fatigue crack growth; finite element method; simulation; wet chamber

\section{INTRODUCTION}

For modern aircraft construction, the increasingly stringent requirements are set in terms of the level of safety in operation and resistance to fracture, especially in aluminium alloys from the AA2000 and AA7000 series. For development of the new, but also for safe exploitation of the existing aluminium alloys of increased-strength and high-strength, it is necessary to know their behavior in the stress concentration zone whose occurrence is the result of corrosive environments, as well as in the presence of a crack [1]

The basic hypothesis from which we start in this paper is that in the elements of aircraft structure exposed to variable load, problems in operation usually occur in zones of stress concentration and primarily in places where the corrosive environment has caused structural destruction of the base material.

The structure of increased-strength and high-strength aluminium alloys, such as 2024-T351 and 7075-T651, which are widely used in aerospace structures, makes them susceptible to localized corrosion. The combined effect of localized corrosion and fatigue load negatively affects the integrity of the structure, which is considered one of the most significant damage mechanisms, which is why it is necessary to understand fatigue damage in combination with corrosion, as well as crack behavior in aluminium alloys for aircraft.

Fracture mechanics parameters, such as fatigue crack growth rate, can be applied to the behavior analysis of aluminium alloys from which highly responsible elements of aircraft structures exposed to operating conditions are made.

The main goal of this work is experimental application of fracture mechanics, investigate the effect of variable load on the structure elements of aircraft made of aluminium alloy of increased-strength and high-strength, with the presence of a crack-type defect in a corrosive environment.

The results of dynamic tensile tests of compact CT specimens, made of aluminium alloy plates for aircraft 2024-T351 and 7075-T651, are presented. Dynamic uniaxial tensile tests were performed on three groups of specimens (base material, material exposed to moisture for
7 days and material exposed to moisture for 30 days) [6]. A total of 19 specimens were tested, 11 specimens made of aluminum alloy 2024 (5 without corrosion, 3 exposed to moisture for 7 days and 3 exposed to moisture for 30 days) and 8 specimens made of aluminum alloy 7075 (3 without corrosion, 3 exposed to moisture for 7 days and 2 exposed to moisture for 30 days)

\section{TEST SPECIMENS AND TESTING STATION}

The tests were performed in the Laboratory for Metal Materials of the Military Technical Institute of the Ministry of Defense of the Republic of Serbia, using a servohydraulic testing machine.

Table 1 Chemical composition of aluminium alloys 2024-T351 and 7075-T651

\begin{tabular}{|c|c|c|}
\hline \multicolumn{1}{|c|}{ (Share of alloying elements, \%) } \\
\hline Al alloys & $2024-\mathrm{T} 351$ & $7075-\mathrm{T} 651$ \\
\hline Silicon $(\mathrm{Si})$ & 0.50 & 0.40 \\
\hline Iron $(\mathrm{Fe})$ & 0.50 & 0.50 \\
\hline Copper $(\mathrm{Cu})$ & $3.8 \div 4.9$ & $1.2 \div 2.0$ \\
\hline Manganese $(\mathrm{Mn})$ & $0.3 \div 0.9$ & 0.30 \\
\hline Magnesium $(\mathrm{Mg})$ & $1.2 \div 1.8$ & $2.1 \div 2.9$ \\
\hline Chromium $(\mathrm{Cr})$ & 0.10 & $0.18 \div 0.28$ \\
\hline Zinc $(\mathrm{Zn})$ & 0.25 & $5.1 \div 6.1$ \\
\hline Titanium $(\mathrm{Ti})$ & 0.15 & 0.20 \\
\hline Other & 0.15 & 0.15 \\
\hline $\mathrm{Al}$ & The rest & The rest \\
\hline
\end{tabular}

The test specimens were cut from plates of aluminium alloys 2024-T351 and 7075-T651, whose chemical composition, i.e. the share of alloying elements, is shown in Tab. 1 [2]. Standard compact (CT) test specimens for the subject tests, are shown in Fig. 1. Prior to fatigue, two groups of specimens were exposed in a chamber with controlled humidity for 7 and 30 days, in order to create two different levels of initial corrosion damage. The conditions inside the chamber were as follows: relative humidity $R_{\mathrm{W}}=100 \%$ and temperature $t=28 \div 30^{\circ} \mathrm{C}$. These conditions were chosen to accelerate corrosion in a relatively mild corrosive environment.

Specimens for mechanical tensile testing are precisely machined in accordance with the specifications of British Standard BS 7448-1:1991. A compact (CT) specimen with a straight notch was chosen for testing, where the effective width is equal to twice the value of the thickness, $W=2 B$ 
[3]. The width of the specimen $W$ is $50 \mathrm{~mm}$, the thickness of the specimen $B$ is $25 \mathrm{~mm}$ and the length of the initial crack a is $15.5 \mathrm{~mm}$. The specimens were cut and finished to obtain the required surface.
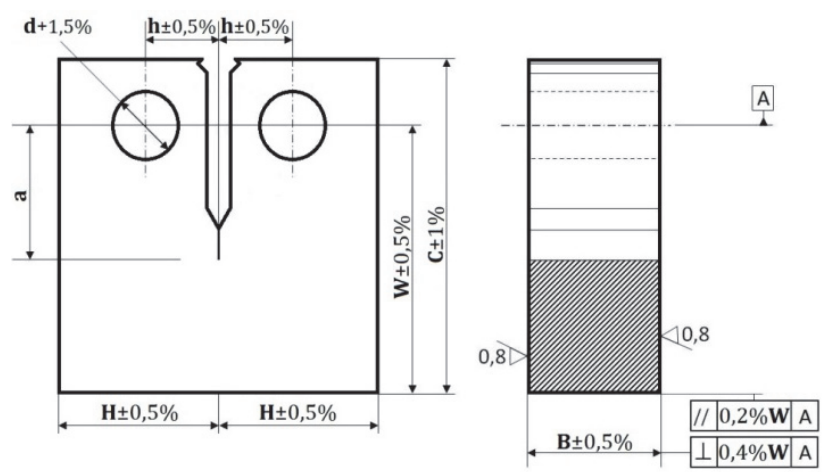

Figure 1 Appearance of a compact (CT) specimen with a straight notch [3]

After exposing the specimens in the described corrosive environment, they, together with a group of specimens that were not exposed to corrosive action, were subjected to a dynamic uniaxial tensile test. The tensile test was performed on specimens of the described aluminium alloys, at room temperature $\left(t=25^{\circ} \mathrm{C}\right)$, in a laboratory environment (relative humidity $R_{\mathrm{W}}=55 \%$ ), using a SHIMADZU ServoPulser E-type servo-hydraulic test machine, type SFL-100KN (Fig. 2).

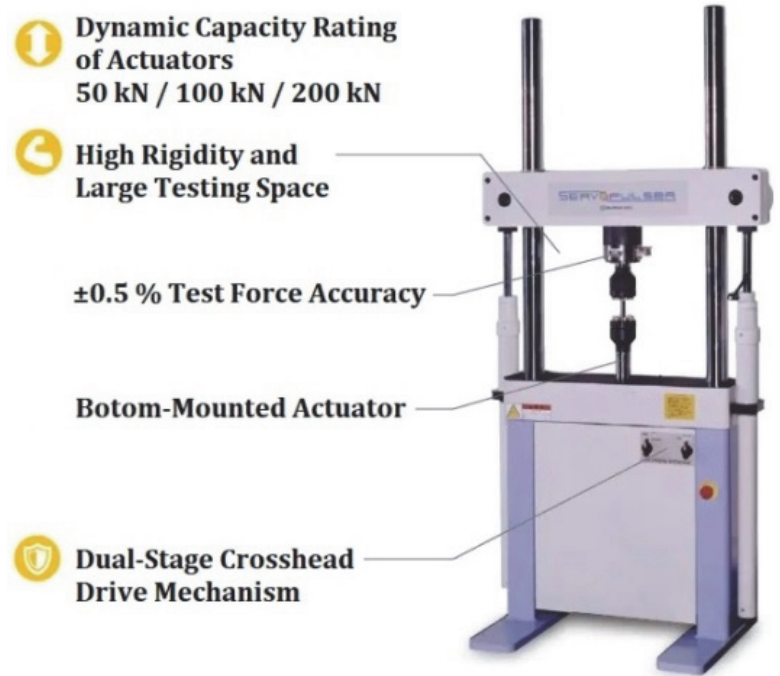

Figure 2 SHIMADZU ServoPulser E-type servo-hydraulic test machine, with basic characteristics [4]

The Shimadzu Servopulser is a complete dynamic behavioral evaluation system with fully digital electrohydraulic servo controller "4830" with high speed loading and data acquisition. The 4830 Controller incorporates full digital control of all elements, including waveform generation, automatic gain control, alarm functions, measurement amplifiers, shockless control switching, and servoamplifiers. Optional application software (Windows versions available) help users through every step to data processing [4].

The study of uniaxial fatigue of constant amplitude was successively performed on three groups of specimens in a laboratory environment. Three repeated tests were performed, under the same load conditions, for each case of corrosion.

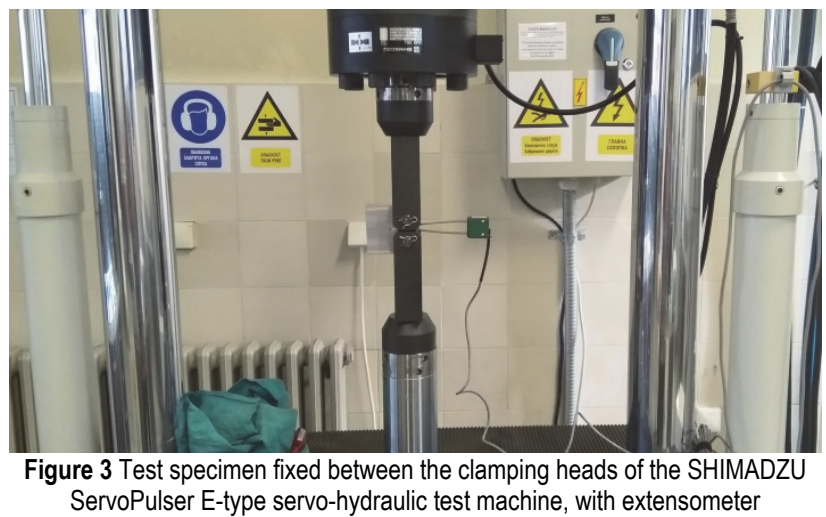

Fig. 3 shows the experimental setup, test specimen fixed between the clamping heads of the servo-hydraulic test machine, with extensometer. Maximum tensile strain applied axially was $F=20 \mathrm{kN}$, with the stress ratio $R=0,1$ and a frequency of $f=15 \mathrm{~Hz}[7]$.

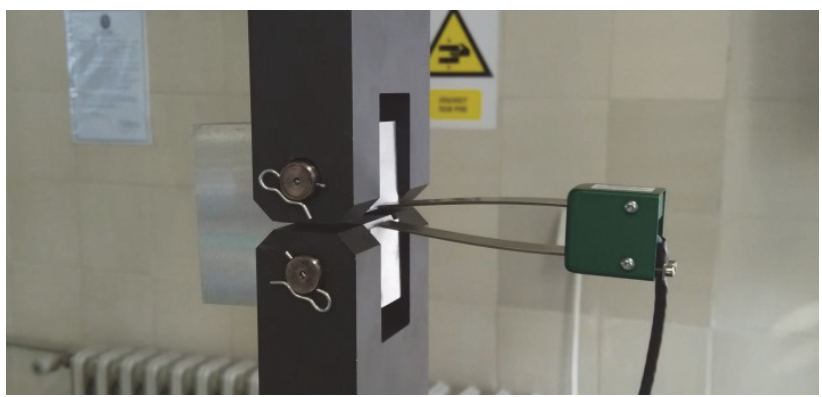

Figure 4 Installation of extensometer

Grips for CT test specimens and extensometer, shown in Fig. 4, are designed for tensile test specimens and are compliant with ASTM E399 and E1820 standards [4].

The collected results are automatically stored in a Microsoft Office Excel file, so that appropriate diagrams can be drawn and fracture mechanics parameters analyzed.

\section{TEST RESULTS}

The resistance of the material to stable fatigue crack growth under cyclic loading is expressed through the crack length a in relation to the number of cycles $N$ or as the fatigue crack growth rate $\mathrm{d} a / \mathrm{d} N$ depending on the change in load intensity factor $\Delta K$. These approaches are particularly important for assessing the impact of fatigue crack growth on the life of structural components. The basic data for predicting the fatigue crack growth are mainly determined based on the results of the cyclic loading of prestressed specimens (the specimens containing the crack). The crack length is measured as a function of elapsed cycles and these data are subjected to numerical analysis to determine the crack growth rates.

The fracture mechanics assumes that the fatigue crack growth in the engineering structure occurs at the same values of da/dN as in the prestressed specimen, when the load conditions are the same for both configurations. Therefore, the fatigue life of the fatigue crack can be estimated by numerical integration of the crack growth rates determined in the experimental test specimen [11]. 


\subsection{Fatigue Crack Life}

The fatigue crack growth curve as a function of the number of cycles, for one of the tested specimens of AA2024-T351, without previous corrosion, is shown in Fig. 5. During the early phase of the action of the variable load, a small increase of the fatigue crack can be noticed, while after the point of bending, there is a faster growth of the fatigue crack and finally a fracture occurs.

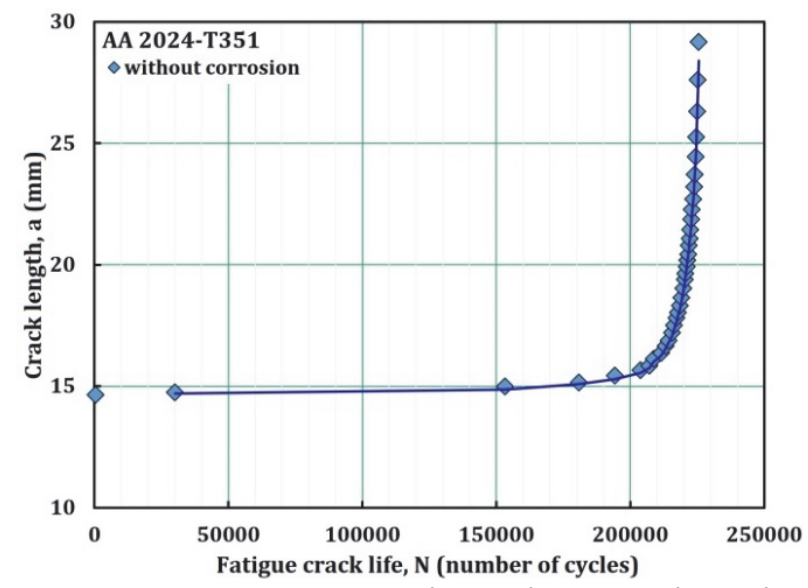

Figure 5 Fatigue crack growth curve, as a function of the number of cycles, for a test specimen of AA2024-T351
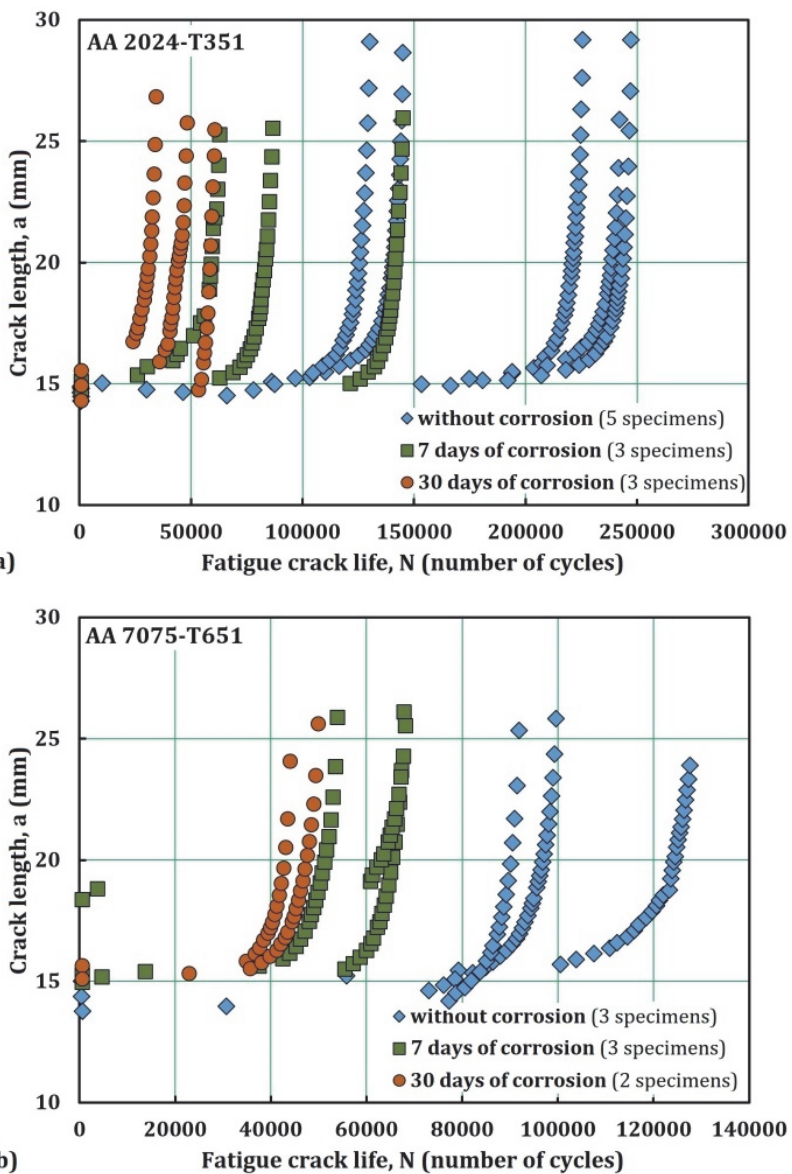

Figure 6 Fatigue crack growth curves, as a function of the number of cycles, for specimens of (a) AA2024-T351 and (b) AA7075-T651, with corrosion exposure times of 0,7 and 30 days

Fig. 6 shows the experimental curves of fatigue crack growth as a function of the number of cycles, for specimens of AA2024-T351 and AA7075-T651, with the time of exposure to the corrosion of 0,7 and 30 days, which reflect the development of cracks induced by fatigue in specimens with different levels of initial damage from corrosion.

Fig. 7 shows the fatigue life of the test specimens AA2024-T351 and AA7075-T651, with different levels of localized corrosion damage.

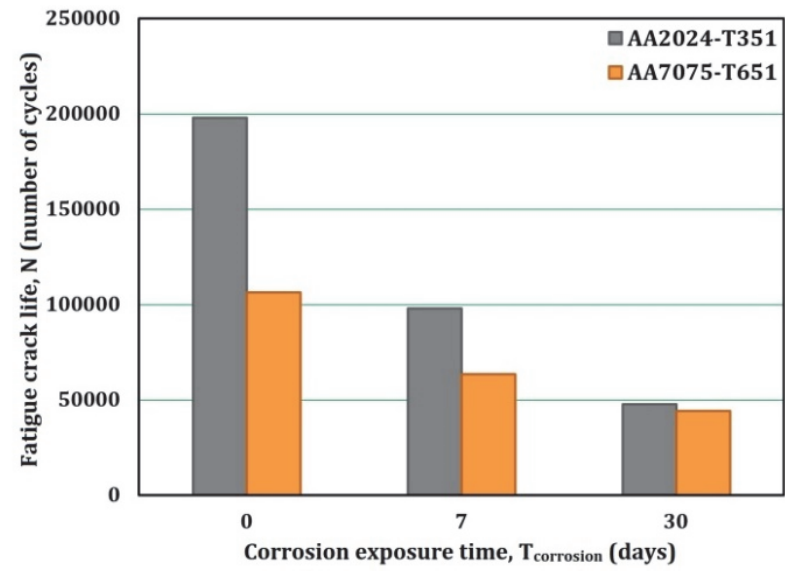

Figure 7 Fatigue crack life, as a function of pre-corrosion time, for AA2024-T351 and AA7075-T651 specimens, with corrosion exposure times of 0,7 and 30 days

The average number of fatigue cycles to fracture is $19.80 \times 10^{4}, 9.80 \times 10^{4}$ and $4.77 \times 10^{4}$ for specimens of AA2024-T351 and $10.64 \times 10^{4}, 6.33 \times 10^{4}$ and $4.41 \times 10^{4}$ for specimens of AA7075-T651, which corresponds to specimens with the times of the previous corrosion exposure of 0,7 and 30 days, respectively.

For AA2024-T351, the fatigue life was reduced by $50.50 \%$ after 7 days of exposure compared to the case without corrosion and by $75.90 \%$ after 30 days of exposure in a corrosive environment. For AA7075-T651 the reduction in fatigue life is $40.44 \%$ and $58.56 \%$, after 7 and 30 days of exposure in a corrosive environment, respectively.

These results clearly show that the presence of localized corrosion adversely affects the fatigue performance of aluminium alloys AA2024-T351 and AA7075-T651 [8].

\subsection{Fatigue Crack Growth Rate}

The typical relationship between the fatigue crack growth rate and load intensity factor, which is characteristic of most aluminium alloys, including alloys AA2024-T351 and AA7075-T651, when tested in a corrosively active working environment, is often classified into three areas (Fig. 8).

Area I covers a very slow degree of crack growth $\left(10^{-5}\right.$ $\mathrm{mm} /$ cycle), where the curves approach the limit value of the stress intensity factor (still immeasurable crack growth). As can be seen, within this area there is a threshold of fatigue load intensity, below which there seems to be no growth of the existing crack. For many long-term load applications, fatigue crack growth at a very slow rate is a major part of the life of a structural component. From the point of view of fracture mechanics, knowledge of fatigue crack growth rates at low $\Delta K$ is very important, since these rates correspond to the early stages 
of crack formation and growth, where it is still possible to take appropriate corrective measures [9].

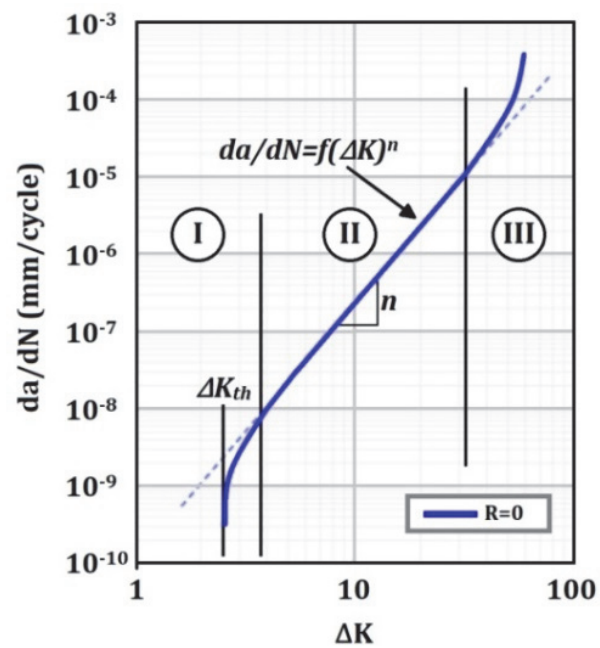

Figure 8 Relationship between fatigue crack growth rate and load intensity factor [5]

Area II covers the growth of the macro crack $\left(10^{-5}\right.$ to $10^{-3} \mathrm{~mm} /$ cycle) and this is the area that lasts the longest in practical cases. This area is often characterized by a linear relationship between the fatigue crack growth rate, $\mathrm{d} a / \mathrm{d} N$, and the change in load intensity factor, $\Delta K$.

Area III covers the area of rapid crack growth (greater than $10^{-3} \mathrm{~mm} /$ cycle) and represents the area of instability and final fracture [9].

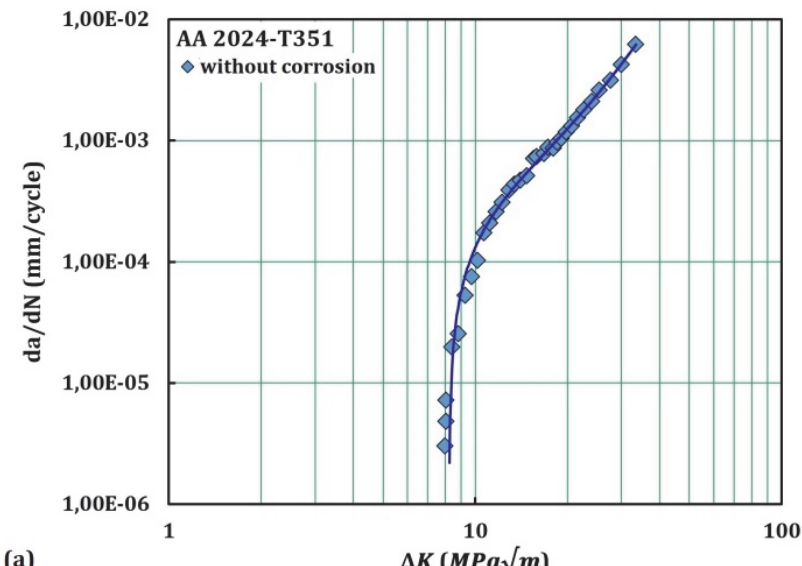

(a)

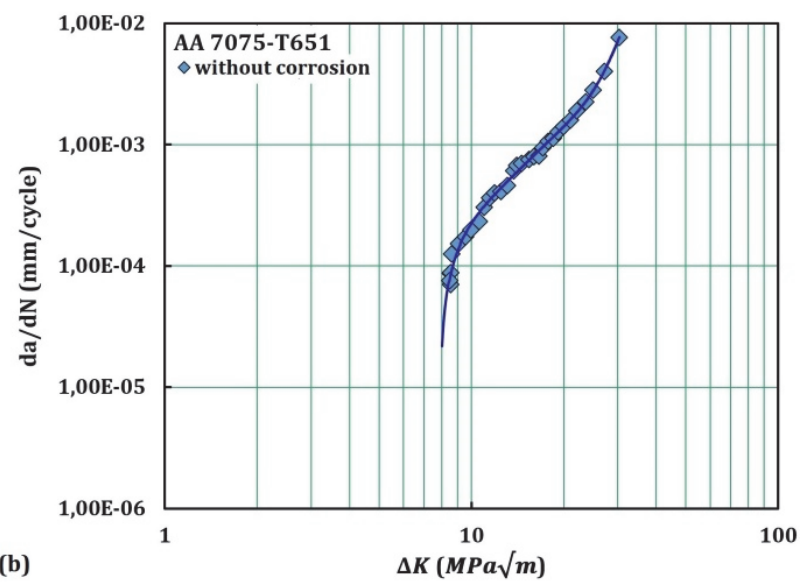

Figure 9 Influence of the stress intensity factor on crack growth rate, da/d $N=$ $f(\Delta K)$, for specimens of (a) AA2024-T351 and (b) AA7075-T651, without previous corrosion
Fig. 9 shows the fatigue crack growth rate curves for specimen AA2024-T351 and AA7075-T651, without previous corrosion, which show the influence of stress intensity factors on the crack growth rate. In Area I, where there are small stresses around the crack tip, values of the stress intensity factor are low and the crack progresses at a low rate, but it gradually increases with the transition to Area II. At higher values of the stress intensity factor, in Area II, stable crack propagation begins at a higher and constant rate. Unstable growth in Area III means crack propagation at a high rate. The crack growth rate increases as the breaking point approaches.

Figs. 10 and 11 present a comparative overview of the crack growth rate curves in specimens AA2024-T351 and AA7075-T651, with corrosion exposure times of 0,7 and 30 days. As can be seen, the fatigue crack growth rate increases with increasing crack length and this change is qualitatively similar for both types of alloys. In general, the results show that, regardless of the environment, the fatigue crack growth rates are quite similar for both aluminium alloys. On the other hand, it is noticeable that the crack growth rates in specimens of base material (without corrosion) are of magnitude $10^{-5}$ to $10^{-3} \mathrm{~mm} / \mathrm{cycle}$, while in corroded specimens crack growth rates are mostly of magnitude $10^{-4} \mathrm{~mm} /$ cycle [10].

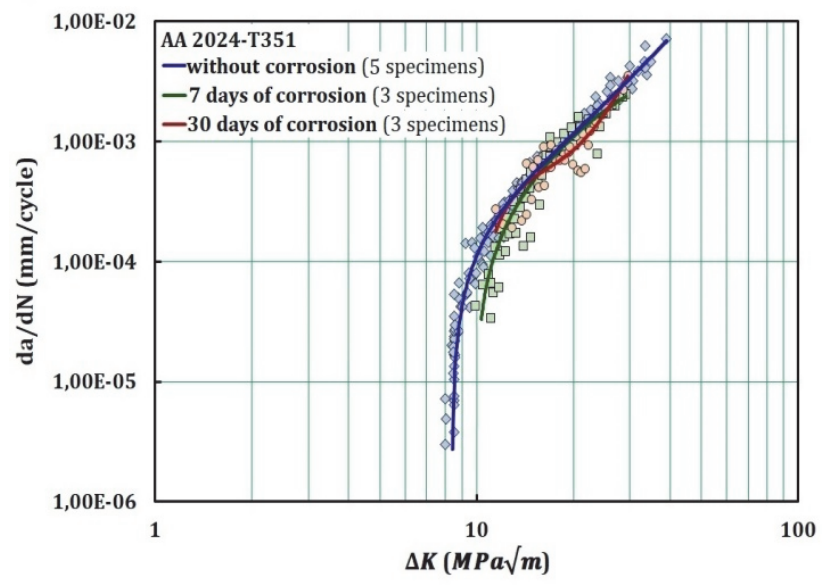

Figure 10 Crack growth curves, da/d $N=f(\Delta K)$, for specimens of AA2024-T351, with corrosion exposure times of 0,7 and 30 days

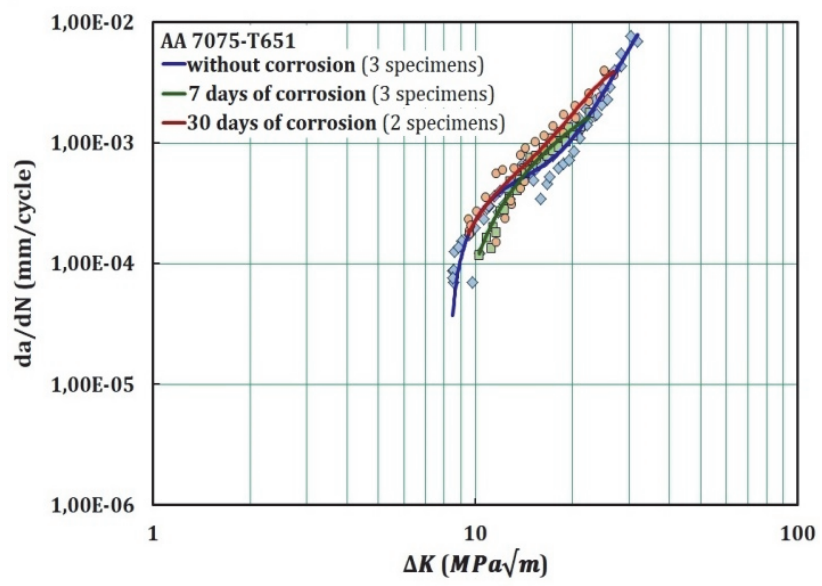

Figure 11 Crack growth curves, da/d $N=f(\Delta K)$, for specimens of AA7075-T651, with corrosion exposure times of 0,7 and 30 days

In the continuation of the paper, Figs. 12, 13 and 14 present comparative reviews of the fatigue crack growth 
rate curves, $\mathrm{d} a / \mathrm{d} N$, depending on the variation of the stress intensity factor, $\triangle K$, measured in specimens of AA2024T351 and AA7075-T651, for each of the three individual corrosion exposure times.

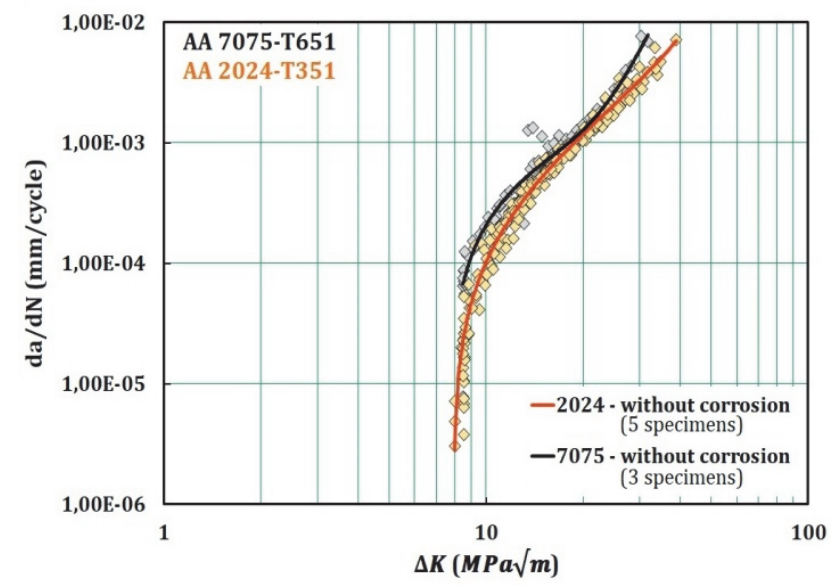

Figure 12 Crack growth curves, da/d $N=f(\Delta K)$, for specimens AA2024-T351 and AA7075-T651, without prior corrosion

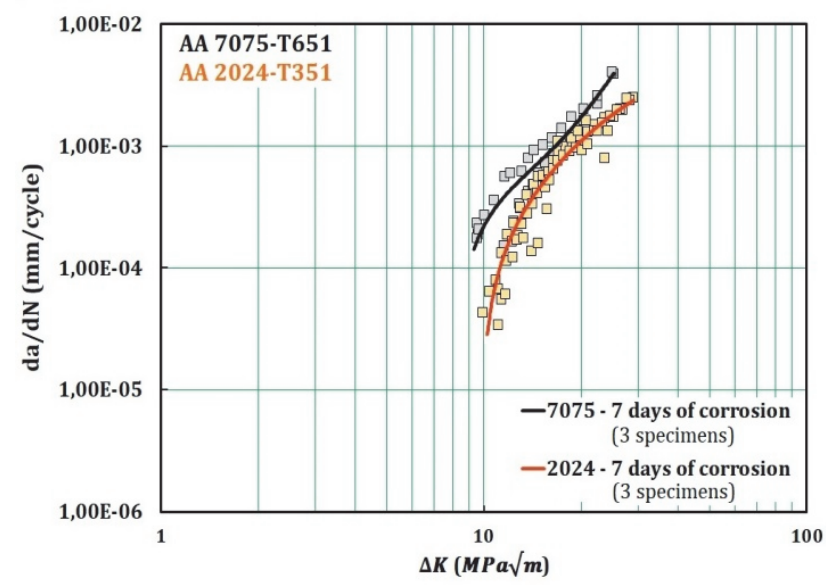

Figure 13 Crack growth curves, $\mathrm{da} / \mathrm{d} N=f(\Delta K)$, for specimens AA2024-T351 and AA7075-T651, with a corrosion exposure time of 7 days

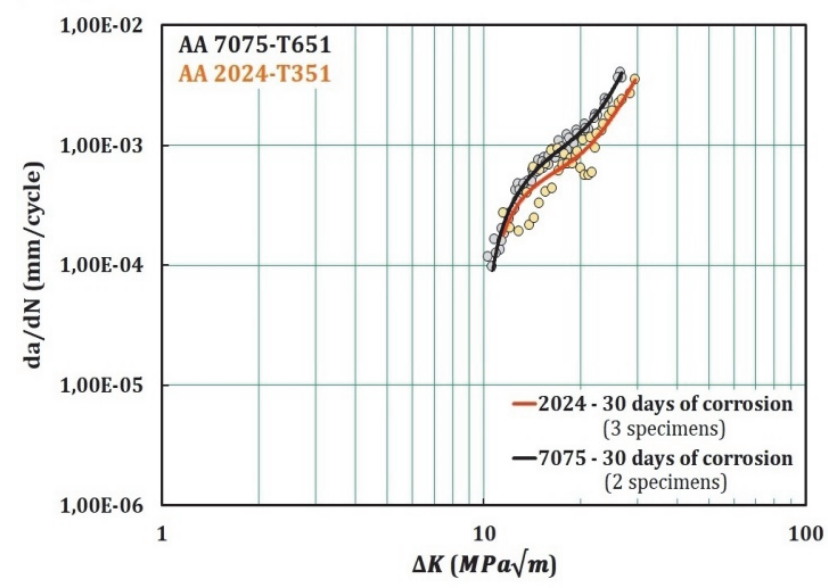

Figure 14 Crack growth curves, da/d $N=f(\Delta K)$, for specimens AA2024-T351 and AA7075-T651, with a corrosion exposure time of 30 days

Finally, a significant degradation effect of corrosion was observed in the specimens of both aluminium alloys. Namely, it is evident that in corroded specimens, under the same loading conditions, unstable growth and crack propagation at maximum speed, and finally specimen fracture, occur at crack lengths that are smaller than in the case of specimens without previous corrosion.

\section{SIMULATION OF FATIGUE CRACK GROWTH IN ALUMINIUM ALLOY 2024-T351}

This section presents the results of crack growth simulation using the software package ANSYS Workbench based on the finite element method [12]. The idea behind the numerical simulation was to develop useful finite element model of cracked CT specimen that can be used in evaluation of fatigue life for loading conditions different from those used in experiments.

The simulation was done using the SMART (Separating, Morphing, Adaptive and Remeshing Technology) tool, which is the latest tool for calculating crack growth in ANSYS Mechanical. In addition to calculating the fracture parameters $K_{1}$, SMART supports the calculation of the fatigue life cycle using the Paris law.

In this case, the subject of the analysis is the estimation of the number of load cycles to fracture for the aluminum alloy specimen 2024-T351, without prior exposure of the specimen to corrosion, which was previously analyzed experimentally.

Static structural analysis combined with fracture analysis was carried out, including the use of Paris law for evaluation of the number of cycles. Changeable values of pressure were applied, calculated using values of force measured in the experiment and the area of hole where force was acting. The other hole of the specimen was fixed (Fig. 15), while displacement of two parallel faces (yellow color) of specimen was allowed only in the direction of external force. The pressure was applied in 36 time steps shown in Tab. 2.

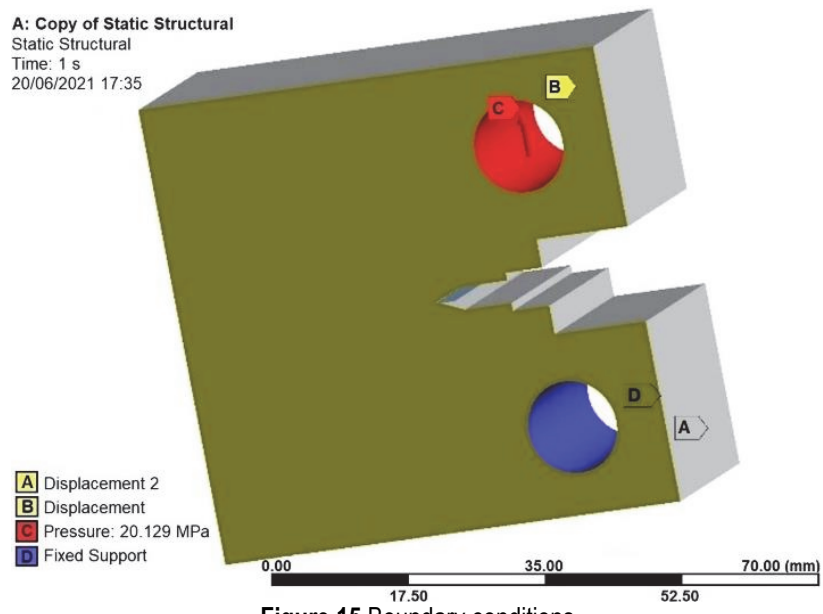

Figure 15 Boundary conditions

The basic data of the FEA model are as follows:

- element type used is parabolic tetrahedron elements SOLID187,

- number of elements of initial model: 88605 ,

- number of nodes of initial model: 127116,

- total elements defined after remeshing: 153413,

- $\quad$ total nodes defined after remeshing: 216879.

Fig. 16 and 17 show the stress state in the specimen at the beginning and at the end of the simulation and their purpose is to show that the stress field around the crack tip is not influenced by boundary conditions. The stress values 
around the crack tip are increasing as the crack grows and are used for stress intensity factors calculations necessary for the evaluation of the number of cycles. Also, these figures show the difference between the initial and final cracked specimen, as well as the difference in FEA mesh between the initial and final FEA model.

Table 2 Values of pressure used in simulation

\begin{tabular}{|c|c|c|c|c|c|}
\hline $\begin{array}{c}\text { Time step } \\
\text { /s }\end{array}$ & $\begin{array}{c}\text { Pressure / } \\
\text { Mpa }\end{array}$ & $\begin{array}{c}\text { Time step } \\
\text { / s }\end{array}$ & $\begin{array}{c}\text { Pressure / } \\
\text { Mpa }\end{array}$ & $\begin{array}{c}\text { Time step } \\
/ \mathrm{s}\end{array}$ & $\begin{array}{c}\text { Pressure / } \\
\text { Mpa }\end{array}$ \\
\hline 0.0 & -9.7257 & 0.34286 & -13.187 & 0.68571 & -17.234 \\
\hline $2.8 \mathrm{E}-02$ & -9.9697 & 0.37143 & -13.694 & 0.71429 & -17.509 \\
\hline $5.7 \mathrm{E}-02$ & -9.8523 & 0.4 & -14.025 & 0.74286 & -17.86 \\
\hline $8.5 \mathrm{E}-02$ & -9.7626 & 0.42857 & -14.309 & 0.77143 & -18.164 \\
\hline 0.11429 & -10.038 & 0.45714 & -14.715 & 0.8 & -18.489 \\
\hline 0.14286 & -10.43 & 0.48571 & -15.13 & 0.82857 & -18.809 \\
\hline 0.17143 & -10.981 & 0.51429 & -15.542 & 0.85714 & -19.081 \\
\hline 0.2 & -11.359 & 0.54286 & -15.82 & 0.88571 & -19.365 \\
\hline 0.22857 & -11.748 & 0.57143 & -16.076 & 0.91429 & -19.682 \\
\hline 0.25714 & -12.02 & 0.6 & -16.345 & 0.94286 & -19.901 \\
\hline 0.28571 & -12.37 & 0.62857 & -16.651 & 0.97143 & -20.083 \\
\hline 0.31429 & -12.856 & 0.65714 & -16.889 & 1.0 & -20.129 \\
\hline
\end{tabular}

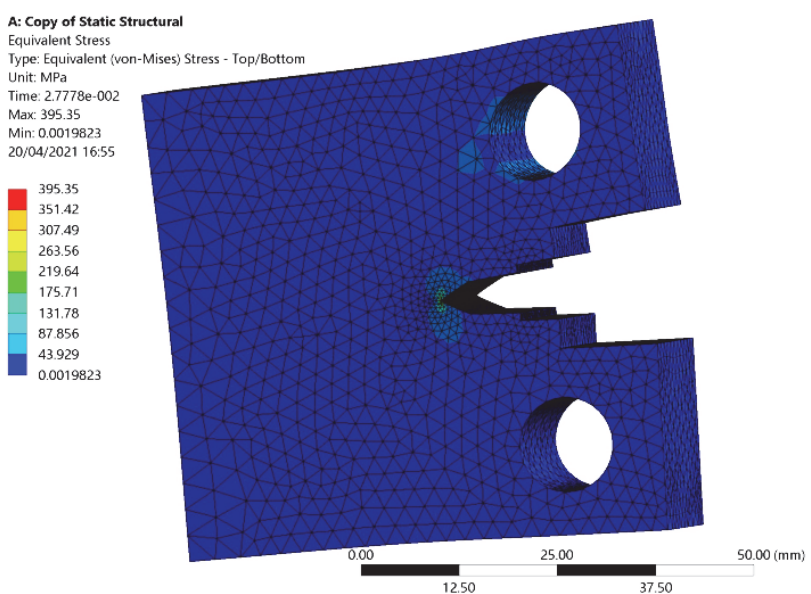

Figure 16 Stress state in the test specimen at the beginning of the simulation (for specimen of AA2024-T351, without previous corrosion)

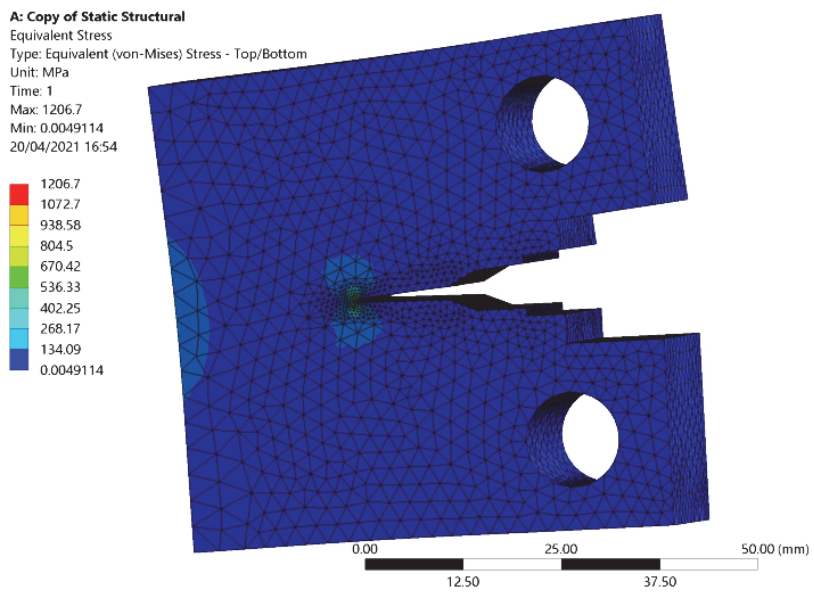

Figure 17 Stress state in the test specimen at the end of the simulation (for specimen of AA2024-T351, without previous corrosion)

Fig. 18 presents a comparative overview of the results obtained experimentally and numerically by simulation.

By comparing the results obtained experimentally and numerically by simulation, it can be concluded that they match relatively well. The differences in the final number of cycles is around 15\% (FEM gave more conservative estimation). There could be a smaller difference, but since in different experiments with fatigue cracks under the same test conditions, significant deviations in the results might be obtained too, numerical value of the number of cycles might be considered acceptable. Certainly, the numerical model must be further improved. A variable load (rather than a constant one) was used, which corresponds more to the measured values of the force in the experiment.

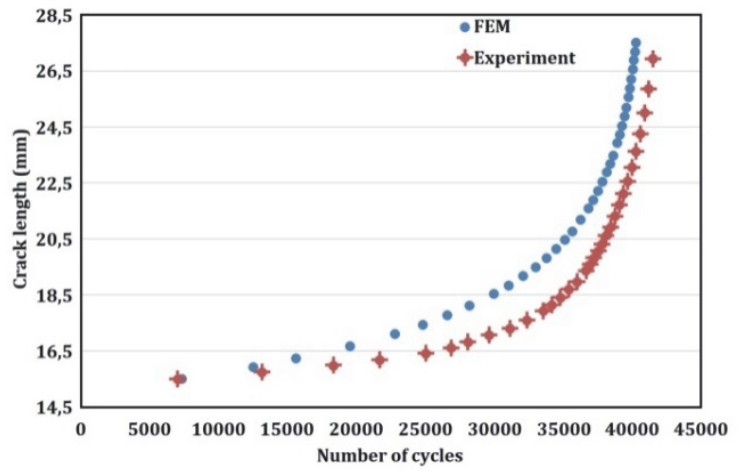

Figure 18 Comparison of numerical and experimental values (for specimen of AA2024-T351, without previous corrosion)

\section{CONCLUSION}

Parameters of fracture mechanics, such as crack fatigue life and fatigue crack growth rate of aluminum alloys 2024-T351 and 7075-T65, under the action of corrosion and fatigue were studied experimentally, and the following conclusions were obtained.

Regardless of the time of exposure to corrosive action, it is evident that there is a difference in fatigue crack growth rates recorded in the tested specimens, depending on the aluminium alloy of which the specimen is made, with values of speeds in specimens AA2024-T351 lower than in specimens AA7075-T651.

When it comes to life of a fatigue crack, as well as its length, a significant degradation effect of corrosion is noticeable in specimens of both types of aluminium alloy AA2024-T351 and AA7075-T651. Namely, it has been shown that previous corrosion leads to accelerated fatigue crack growth and thus to a reduction of fatigue crack life, so that with increasing exposure time to previous corrosion, the number of load cycles decreases.

In addition, it has been shown that under the same load conditions, unstable growth and crack propagation at maximum rate and ultimately specimen fracture, in corroded specimens occurs at shorter crack lengths than in specimens without previous corrosion.

Comparing the results obtained experimentally and numerically by simulation, it can be concluded that the differences in the results range up to $15 \%$. But, we must bear in mind that fatigue is a statistical phenomenon and that results can deviate significantly from specimen to specimen. However, the Paris coefficients for aluminum alloys 2024, 7075, and other materials - on the basis of which the number of cycles is calculated - must always be determined in experiments: these coefficients are not standard properties of the material (such as modulus of elasticity, for example) and estimated number of cycles depends on how well coefficients have been evaluated in the experiment. On the other hand, it is not easy to replicate experimental conditions in numerical simulations 
especially when an external load is slightly increasing or decreasing over time. This paper shows that when a variable load (pressure) is used instead of a constant load, numerically obtained results have a tendency to be closer to experimental ones.

\section{REFERENCES}

[1] Dursun, T. \& Soutis, C. (2014). Recent developments in advanced aircraft aluminium alloys. Materials \& Design, 56, 862-871. https://doi.org/10.1016/j.matdes.2013.12.002

[2] ASTM B209M-04. (2004). Standard Specification for Aluminium and Aluminium Alloy Sheet and Plate. West Conshohocken, PA. American Society for Testing and Materials International. https://doi.org/10.1520/B0209M-04

[3] BS 7448-1:1991. (1991).Fracture Mechanics Toughness Tests - Part 1: Method for Determination of $K_{I c}$, Cricital CTOD and Cricital J Values of Metallic Materials. British Standards Institution.

[4] See https://www.ssi.shimadzu.com

[5] See https://mechanicalc.com/reference/fatigue-crack-growth

[6] Haipeng, S., Changchun, L., Hao, Z., \& Sean, B. L. (2018). A DIC-Based Study on Fatigue Damage Evolution in PreCorroded Aluminum Alloy 2024-T4. Materials, 11(11). https://doi.org/10.3390/ma11112243

[7] Moreto, J., Junior F., Maciel C., Bonazzi L., Junior J., Ruchert C., \& Filho W. (2015). Environmentally-assisted Fatigue Crack Growth in AA7050-T73511 Al Alloy and AA2050-T84 Al-Cu-Li Alloy. Materials Research, 18(6), 1291-1297. https://doi.org/10.1590/1516-1439.018915

[8] Yang, H., Wang, Y., Wang, X., Pan, P. \& Jia, D. (2016). The Effects of Corrosive Media on Fatigue Performance of Structural Aluminum Alloys. Metals, 6, 160. https://doi.org/10.3390/met6070160

[9] Petrašinović, D. (2012). Aircraft Metal Wing Structural Parts Fatigue Life Analasys. PhD Thesis. University of Belgrade, Faculty of Mechanical Engineering.

[10] Zhang, T., He Y., Li C., Zhang T., \& Zhang, S. (2020). Effect of Alternate Corrosion and Fatigue on Fatigue Crack Growth Characterization of 2024-T4 Aluminum Alloy. Mathematical Problems in Engineering. https://doi.org/10.1155/2020/7314241

[11] Bucci, R. J., Nordmark, G., \& Starke, E. A. (1996). Selecting Aluminum Alloys to Resist Failure by Fracture Mechanisms. ASM Handbook, 19, 771-812. https://doi.org/10.31399/asm.hb.v19.a0002406

[12] See https://www.ansys.com

\section{Contact information:}

Zoran PETROVIĆ, master, PhD Candidate

(Corresponding author)

Serbian Army, General Staff of the Serbian Army, Logistics Directorate (J-4),

E-mail: pzoran.pele@gmail.com

Aleksandar GRBOVIĆ, PhD, Professor

Faculty of Mechanical Engineering, University of Belgrade,

Department of Aerospace Engineering

Kraljice Marije 16, Belgrade

Zijah BURZIĆ, PhD

Military Technical Institute, Belgrade,

Ratka Resanovića 1, Belgrade

Srđa PERKOVIĆ, master, PhD Candidate

Military Technical Institute, Belgrade,

Ratka Resanovića 1, Belgrade 